\title{
VALIDATION OF REGIONAL GEOID MODELS FOR POLAND: LOWER SILESIA CASE STUDY
}

\author{
Katarzyna STEPNIAK ${ }^{1)}$ *, Radoslaw BARYLA ${ }^{1)}$, Jacek PAZIEWSKI ${ }^{1)}$, Pawel GOLASZEWSKI ${ }^{1 \text {, }}$ \\ Pawel WIELGOSZ ${ }^{1)}$, Grzegorz KURPINSKI ${ }^{2)}$ and Edward OSADA ${ }^{3)}$ \\ ${ }^{1)}$ University of Warmia and Mazury in Olsztyn, Faculty of Geodesy, Geospatial and Civil Engineering, \\ Oczapowskiego 1, 10-719 Olsztyn, Poland \\ 2) KGHM Cuprum Ltd Research and Development Centre, Sikorskiego 2-8, 53-659 Wroclaw, Poland \\ ${ }^{3)}$ Wroclaw University of Environmental and Life Sciences, Institute of Geodesy and Geoinformatics, Grunwaldzka 53, \\ 50-357 Wroclaw, Poland \\ *Corresponding author's e-mail: katarzyna.stepniak@uwm.edu.pl
}

\section{ARTICLE INFO}

\section{Article history}

Received 28 April 2016

Accepted 14 September 2016

Available online 23 September 2016

\section{Keywords:}

\section{GNSS}

Satellite leveling

Precise leveling

Quasigeoid models

\begin{abstract}
Nowadays, the high accuracy of the horizontal coordinates obtained from GNSS measurements is easily achievable. On the other hand, the precision of GNSS-derived heights is clearly lower. Nevertheless, state of the art measurement technique, field surveying equipment, data processing software and algorithms allow achieving millimeter-level accuracy for ellipsoidal heights. However, in order to obtain the normal heights from GNSS measurements, the application of precise quasigeoid model is necessary. Nowadays, there are several available guasiqeoid models covering the area of Poland, e.g. PL-geoid-2011; EGM2008; "leveling geoid 2001"; European Gravimetric Quasigeoid model EGG2008. In addition, a high-accuracy regional quasigeoid model for the Lower Silesia region was developed in 2015.

In this paper, we investigate performance of the application of the selected quasigeoid models to satellite leveling on the basis of test precise leveling network established at the area of Lower Silesia in Poland. In this region, simultaneous precise geometric and satellite leveling measurements were carried out on over $1000 \mathrm{~km}$ of leveling lines and over 100 GNSS sites. The results show that the current relative accuracy of the most accurate geoid models is better than $10 \mathrm{~mm}$.
\end{abstract}

\section{INTRODUCTION AND MOTIVATION}

Nowadays, extensive studies are carried out in the field of GNSS algorithm and methodology development. Recent achievements allow for application of new GNSS signals in precise positioning (Cellmer et al. 2013; Paziewski and Wielgosz, 2014; Odolinski et al.; 2014; Li et al., 2015a; Paziewski and Wielgosz, 2016). According to these studies centimeter-level horizontal coordinates of the points can be obtain rapidly and reliably. On the other hand, structural and ground deformation applications require the highest precision especially of the height component. This can be achieved using precise spirit leveling or advanced methodology for precise satellite leveling (Sheng, 2005). In order to obtain normal heights from GNSS leveling, the geoidellipsoid undulation model accuracy is of crucial interest. In addition, atmospheric delay (Wielgosz et al., 2011; Wielgosz et al., 2013), hardware biases (Gao et al., 2001; Li et al., 2015b), errors related to the satellite and receiver antenna phase center (Schmitz et al., 2002; Schmid and Rothacher, 2003; Stepniak et al., 2015) need to be precisely modeled and eliminated.
The satellite gravity missions have significantly amended determination of global geopotential models of the Earth's gravity field (Bilker et al., 2003; Daho, 2010; Kotsakis and Kotsambalos, 2010). The models have been improved in degree and order of spherical harmonic, which led to enhancement of their spatial resolution. One of the predominant accomplishment in the field of Earth's geopotential modelling is the EGM2008 global model. The model is complete to degree and order of 2159 and contains additional spherical harmonic coefficients up to degree of 2190 and order of 2159 (Pavlis et al., 2012). Studies showed that it is possible to obtain residuals between EGM2008 geoid undulations and GPS/leveling at the level of \pm 5 to $\pm 10 \mathrm{~cm}$ (Pavlis et al., 2012). On the other hand, global geoid models do not often coincide with the national height datum. What is more, in many countries quasigeoid models are applied as the reference datum in contrary to the geoid. By combination of global geopotential models with local gravity information, GNSS measurements and spirit leveling regional geoid/quasigeoid models have been developed that are suitable to national heights networks. Nowadays in Poland, the legacy height 
Table 1 Characteristic of selected quasigeoid models developed for the territory of Poland.

\begin{tabular}{|c|c|c|c|c|c|c|}
\hline $\begin{array}{l}\text { Geoid } \\
\text { model }\end{array}$ & General methodology & $\begin{array}{c}\text { Number of GNSS } \\
\text { points }\end{array}$ & $\begin{array}{c}\text { Geometric } \\
\text { leveling }\end{array}$ & $\begin{array}{c}\text { Size of } \\
\text { outcome } \\
\text { grid }\end{array}$ & $\begin{array}{l}\text { Interpolation } \\
\text { method }\end{array}$ & $\begin{array}{c}\text { Formal } \\
\text { accuracy }\end{array}$ \\
\hline 2001 & $\begin{array}{c}\text { fitting a gravimetric } \\
\text { quasigeoid model } \\
\text { quasi97b into the satellite- } \\
\text { leveling quasigeoid model } \\
\text { QGEOID'PL01 }\end{array}$ & $\begin{array}{c}752 \text { points: } \\
\text { EUVN, EUREF-POL, } \\
\text { POLREF, } \\
\text { Tatry, WSSG }\end{array}$ & no & $1^{\prime} \times 1^{\prime}$ & bilinear & $3.0 \mathrm{~cm}$ \\
\hline 2008 & $\begin{array}{l}\text { based on EGM2008 model } \\
\text { and fitted locally in the } \\
\text { satellite-levelling points }\end{array}$ & $\begin{array}{l}400 \text { points: EUVN, } \\
\text { EUREF-POL, POLREF }\end{array}$ & no & $1^{\prime} \times 1^{\prime}$ & bilinear & $1.7 \mathrm{~cm}$ \\
\hline 2008A & & $\begin{array}{l}141 \text { points: ASG- } \\
\text { EUPOS, EUVN }\end{array}$ & no & $1^{\prime} \times 1^{\prime}$ & bilinear & $1.7 \mathrm{~cm}$ \\
\hline $2008 C$ & & $\begin{array}{l}141 \text { points: ASG- } \\
\text { EUPOS, EUVN }\end{array}$ & no & $0.01^{\circ} \times 0.01^{\circ}$ & bilinear & $1.7 \mathrm{~cm}$ \\
\hline 2011 & $\begin{array}{l}\text { based on EGM2008 model } \\
\text { and fitted locally in the } \\
\text { satellite-levelling points }\end{array}$ & $\begin{array}{c}570 \text { points: ASG- } \\
\text { EUPOS, EUREF-POL, } \\
\text { POLREF, EUVN }\end{array}$ & no & $0.01^{\circ} \times 0.01^{\circ}$ & bilinear & $1.7 \mathrm{~cm}$ \\
\hline $\begin{array}{c}\text { LGOM } \\
2015\end{array}$ & $\begin{array}{l}\text { based on EGM2008 and } \\
\text { PL-geoid-2011 and the } \\
\text { satellite-levelling points }\end{array}$ & $\begin{array}{l}109 \text { points: GPS network } \\
\text { LGOM }\end{array}$ & yes & $0.01^{\prime} \times 0.01^{\prime}$ & bilinear & $0.3 \mathrm{~cm}$ \\
\hline
\end{tabular}

system is PL-KRON86-NH which is the mathematical and physical realization of the European Vertical Reference System (EVRS). This system is relative to the tide gauge in Kronsztad fixed in 1986. However, there are ongoing works to switch to new PLEVRF2007-NH system that is relative to the tide gauge in Amsterdam.

Recently, several regional quasigeoid models have been developed for the territory of Poland, e.g. leveling geoid 2001, geoidpol2008, geoidpol2008A, geoidpol2008C, PL-geoid-2011. These models were derived using different data and are characterized by various accuracy (Pażus et al., 2002; Krynski and Lyszkowicz, 2006). All these models tie geocentric ellipsoid height with Kronsztadt normal heights system. The most recent models - geoidpol2008, geoidpol2008A, geoidpol2008C, PL-geoid-2011 - are based on the Earth Gravitational Model 2008 (EGM2008) and a set of extended satellite-leveling points (Kuczynska-Siehien et al, 2016). Nevertheless leveling geoid 2001 was created by fitting a gravimetric quasigeoid model quasi97b into the satellite-leveling quasigeoid model QGEOID'PL01. All these quasigeoid models were used in this study. In addition, we used a high-accuracy regional quasigeoid model developed for the Lower Silesia region in 2015 - LGOM 2015. Summary of each validated model is shown in Table 1.

In this paper, we investigate the performance of the application of selected regional geoid models available for the territory of Poland to precise GNSS leveling. The analysis is based on the precise GNSS local network established for ground deformation monitoring at the area of Lower Silesia in Poland. In this region, simultaneous precise geometric and satellite leveling measurements were carried out on over $1000 \mathrm{~km}$ of leveling lines. The GNSS baselines between the monitored points were processed using own processing strategy developed for precise local network processing with Bernese 5.2 software (Stepniak et al., 2013). Previous research on precise satellite leveling showed that the antenna calibration models are responsible for considerable bias in the derived height coordinate component (Dawidowicz, 2013). Hence, we decided to carry out the individual relative antenna calibrations using field calibration methodology developed at UWM in Olsztyn (Stepniak et al., 2015). Obtained corrections were used in the processing.

\section{PERFORMANCE ANALYSIS METHODOLOGY AND RESULTS}

The process of normal heights determination using satellite leveling can be performed in several ways, depending on the knowledge of the quasigeoidellipsoid separation (height anomalies $\xi_{i}$ ). In the basic approach, the satellite leveling is performed by transformation of the ellipsoidal heights $\left(h_{i}\right)$ to normal heights $\left(H_{i}\right)$ by utilization of the local height anomalies $\xi$ (Eqn. 1)

$H_{i}=h_{i}-\xi_{i}$

The height anomalies at each point are derived from quasigeoid models by the means of the interpolation. However, in this absolute approach, the final normal heights may be contaminated by systematic shift of the quasigeoid model with respect to the normal heights datum. A more suitable 
approach is the application of the quasigeoid models to satellite leveling in the relative mode. In this way we obtain normal height differences by transformation of ellipsoid height differences and height anomalies differences at leveling baseline between points $i-j$ :

$\Delta H_{i j}=\Delta h_{i j}^{\text {elips }}-\Delta \xi_{i j}$

Another possibility for ellipsoid to normal heights conversion is the application of onedimensional surface transformation $(\mathrm{Xu}, 2007)$. This requires application of several homogenous points with both ellipsoid and normal heights. On the other hand, there is no need for quasigeoid models utilization.

The provided below accuracy analysis of the quasigeoid models was based on absolute (Eqn. 3) and relative (Eqn. 4) comparison between spirit levelingderived $\left(H_{i}^{\text {lev }}\right)$ and GNSS leveling-derived $\left(H_{i}^{\text {sat }}\right)$ heights of the controlled points. In this assessment, the spirit leveling-derived normal heights of benchmark points and height differences over leveling lines are treated as a reference.

Differences between GNSS precise leveling and spirit leveling heights can be derived using equation:

$H^{\text {resid }}=H_{i}^{\text {sat }}-H_{i}^{\text {lev }}$

The absolute analysis of the satellite levelingderived normal heights gives the information about magnitude of the systematic shift of the local geoid model in respect to the height datum. On the other hand, this bias is greatly reduced in the relative approach. The relative approach analysis (Eqn. 3) characterizes mainly the relative accuracy of the quasigeoid model. Differences between GNSS precise leveling and spirit leveling can be derived using equation:

$\Delta H^{\text {resid }}=\Delta H_{t j}^{\text {sat }}-\Delta H_{t j}^{\text {iev }}$

An innovative project of combining satellite leveling with precise geometric leveling in ground deformation analysis was established in 2012 at the part of the Lower Silesia region (Stepniak et al., 2013). In the project, the rigorous field measurements technology together with processing strategy with application of the Bernese software was determined. The processing strategy was suited for application to short GNSS baselines combined in polygons. The computations were carried out using L1 carrier-phase observations. The collected GNSS data were processed in 4-hour sessions. The data processing interval was set to 30 seconds and the elevation cutoff was set to 10 degrees. In order to obtain coordinates with the highest precision and accuracy, the IGS (International GNSS Service) final precise satellite orbits, clocks, Earth rotation parameters and absolute antenna phase center variations and offsets were used (Dow el al., 2009). In addition, CODE's
(Centre of Orbit Determination in Europe) global ionosphere maps were applied to minimize the impact of ionospheric delays on stations coordinates. Also, the monthly differential code biases (DCBs) for satellites and receivers (P1-C1, P1-P2) were used. In the processing, Global Mapping Function - GMF (Boehm et al., 2006) and Chen-Herring gradient model (Chen and Herring, 1997) were applied. ZTD parameters were set up every 2 hours and tropospheric gradient was estimated once per day. The SIGMA method was applied for the ambiguity resolution (Dach et al., 2015).

The field measurements were carried out using patented metal poles allowing for GNSS antennas forced centering over geodetic benchmarks. On the other hand, it was not always possible to conduct GNSS field measurements over the existing leveling benchmarks.

Thus, the auxiliary benchmark points were established in the vicinity of the leveling benchmarks (Fig. 1).

In order to investigate the performance of the application of the current geoid models at Lower Silesia in the satellite leveling, simultaneous classic geometric and satellite leveling measurements were carried out on classic leveling lines including. A total 109 control points and baselines of total $1000 \mathrm{~km}$ were surveyed.

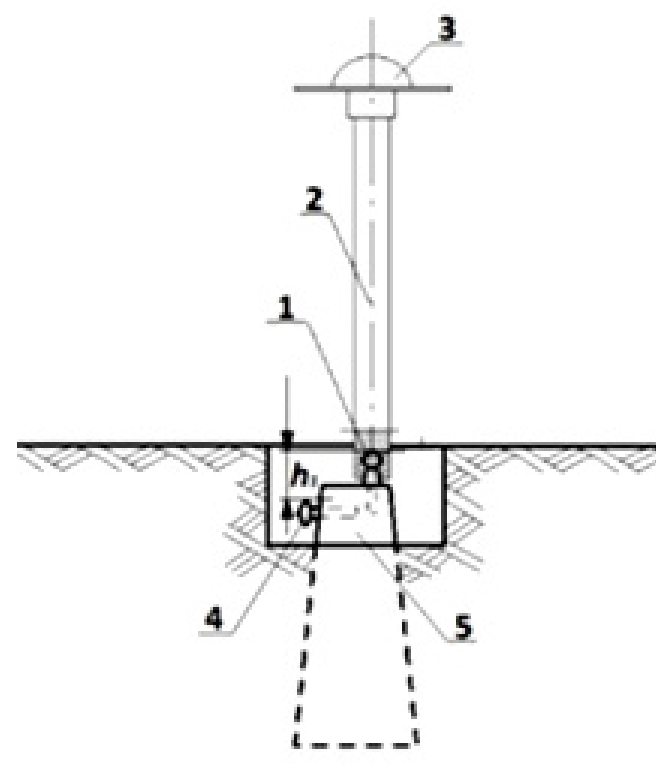

Fig. 1 Forced precise centering of the GNSS antenna (CBR CUPRUM patent);

1 - auxiliary benchmark point, 2 - metal pole; 3 - GNSS antenna; 4 - leveling benchmark; 5 - concrete monument of the leveling benchmark. 
Table 2 Standard deviations and mean values of height anomaly residuals between satellite leveling with the analyzed geoid models and spirit leveling.

\begin{tabular}{lcc}
\hline Geoid model & STD $[\mathbf{m}]$ & Mean [m] \\
\hline $\mathbf{2 0 0 1}$ & 0.0356 & -0.0386 \\
$\mathbf{2 0 0 8}$ & 0.0127 & -0.0288 \\
$\mathbf{2 0 0 8 A}$ & 0.0093 & -0.0222 \\
$\mathbf{2 0 0 8 C}$ & 0.0098 & -0.0219 \\
$\mathbf{2 0 1 1}$ & 0.0103 & -0.0201 \\
LGOM 2015 & 0.0083 & -0.0022 \\
\hline
\end{tabular}

Table 3 Minimal and maximal anomaly residuals of the geoid models.

\begin{tabular}{lcc}
\hline Geoid model & Minimum value of residuals [m] & Maximum value of residuals [m] \\
\hline $\mathbf{2 0 0 1}$ & -0.0726 & 0.0777 \\
$\mathbf{2 0 0 8}$ & -0.0210 & 0.0306 \\
$\mathbf{2 0 0 8 A}$ & -0.0160 & $0.0160(0.0258)$ \\
$\mathbf{2 0 0 8 C}$ & -0.0163 & $0.0187(0.0255)$ \\
$\mathbf{2 0 1 1}$ & -0.0164 & $0.0192(0.0256)$ \\
LGOM 2015 & $-0.0110(-0.0419)$ & $0.0114(0.0335)$
\end{tabular}

Table 4 List of GNSS antennas and their PCO corrections.

\begin{tabular}{lcccc}
\hline Antenna type & S/N & dN [mm] & dE [mm] & dU [mm] \\
\hline TRM5800 NONE & 4442139653 & 0.4 & -1.1 & 5.6 \\
TRM5800 NONE & 4442139640 & 0.5 & -0.7 & 6.3 \\
JAV_GRANT-G3T NONE & 00460 & 0.3 & -3.0 & 3.3 \\
JAV_GRANT-G3T NONE & 01348 & 1.7 & -0.4 & 1.6 \\
ASH701975.01A NONE & 8055 & 3.5 & -0.4 & 5.6 \\
\hline
\end{tabular}

In the analysis we used height anomalies which are based on the geodetic coordinates $(\varphi, \lambda, h)$ of the control points and different interpolation algorithms for each quasigeoid model. The residual height anomalies were determined as differences between GNSS precise leveling (ellipsoidal+quasigeoid model) and spirit leveling (normal) heights. Average differences and standard deviations of the residual anomaly values are shown in Table 2 . The best accuracy can be seen for the LGOM 2015 geoid model (based, among others, on earlier data from satellite and spirit leveling). The lowest values of standard deviation and mean show that using the LGOM 2015 geoid model allows obtain the most accurate results of satellite leveling. The lowest accuracy was obtained for leveling geoid 2001.

Table 3 presents the comparison of the analyzed quasigeoid models based on minimal and maximal residuals (after removing the mean that represents a constant bias of each model). These results are also presented in Figures 2-7. The values in parenthesis include outliers, which can be result of random measurement errors (see also the figures). Local leveling geoid 2015 model (LGOM 2015) presents the best fit in comparison to the quasigeoid determined by the satellite measurements (average residual $\pm 3.6 \mathrm{~mm}$ ). This model has also the most correct shape (residuals are between $-0.0110 \mathrm{~m}$ and $0.0110 \mathrm{~m}$ ). Also, for the geoidpol2008A model the residuals are between $-0.0160 \mathrm{~m}$ and $0.0160 \mathrm{~m}$. The worst results were obtained for the leveling geoid 2001 model (residuals between $-0.0726 \mathrm{~m}$ and $0.0777 \mathrm{~m}$ ).

Previous research on the stability of GNSS antenna phase centers variations (PCV) show that changing the antenna on the monitored point may result in a considerable bias in the derived height coordinate component. Moreover, even for the same antenna type or antennas used for many years, bias of the mean antenna phase center offset (PCO) with respect to the PCO from IGS model can occur. The 


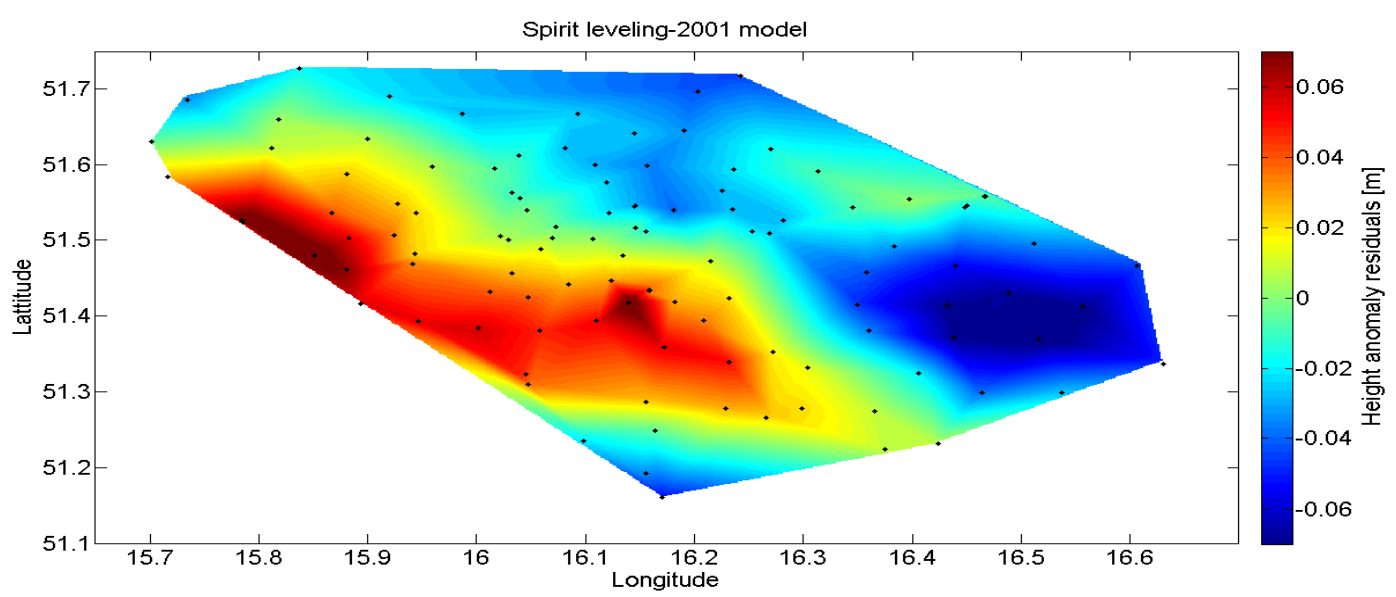

Fig. 2 Height anomaly residuals of the 2001 model.

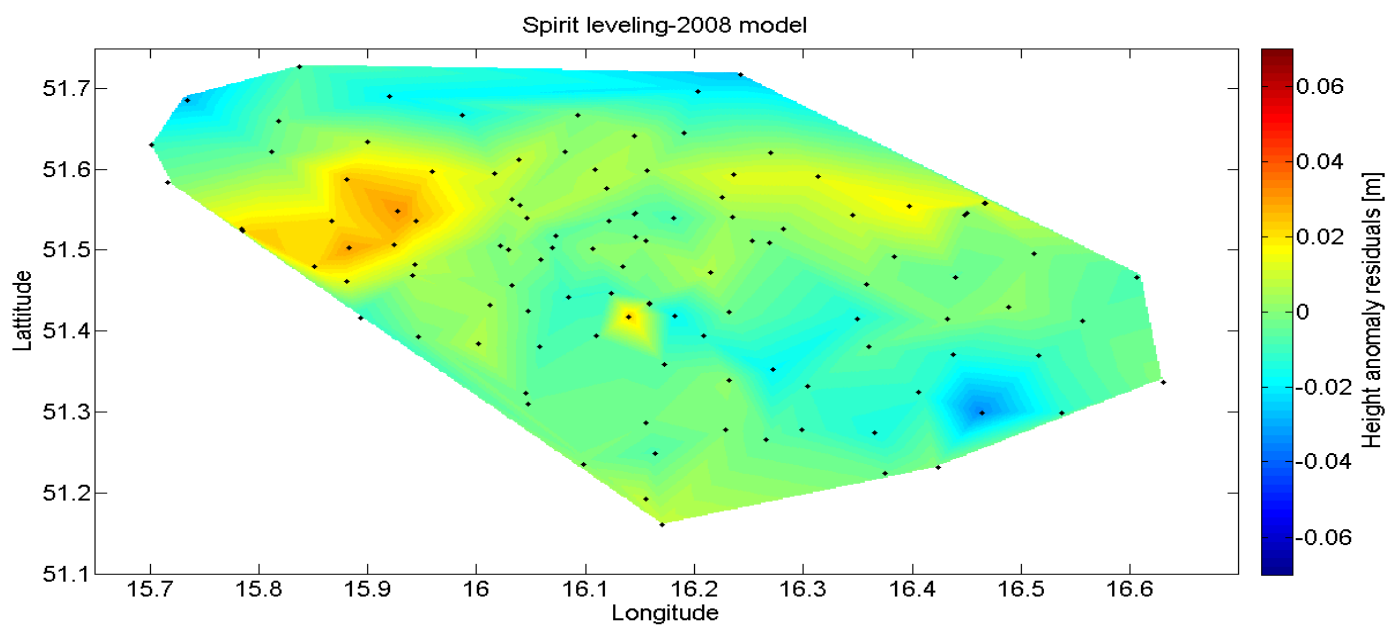

Fig. 3 Height anomaly residuals of the 2008 model.

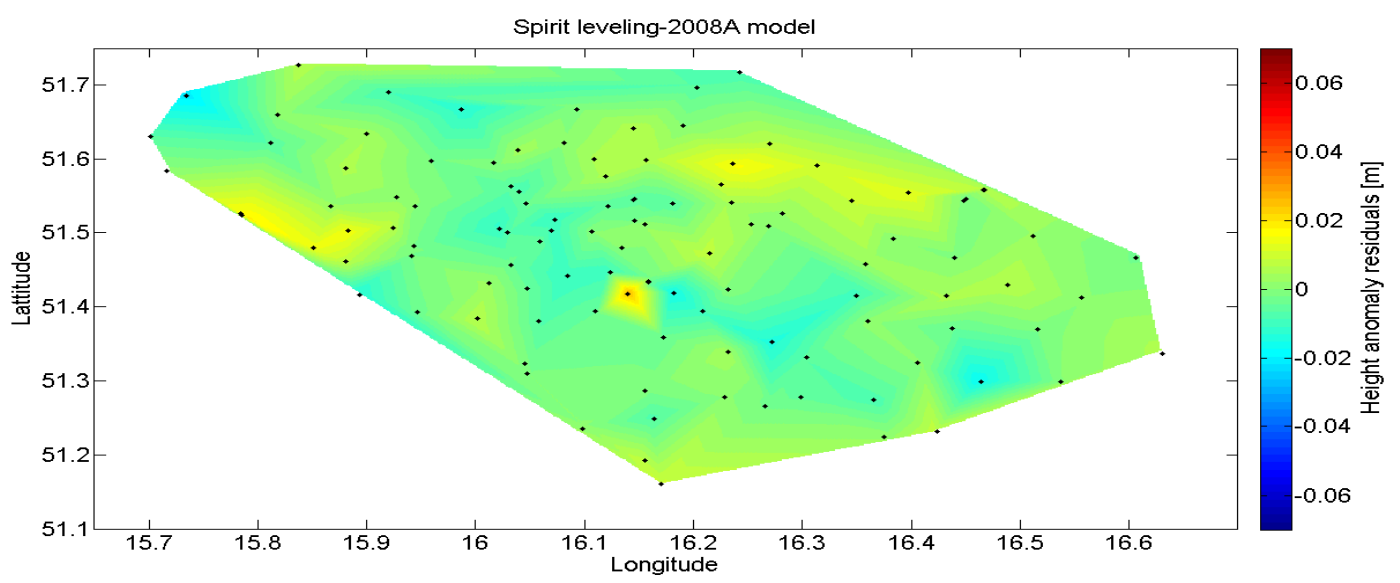

Fig. 4 Height anomaly residuals of the 2008A model. 


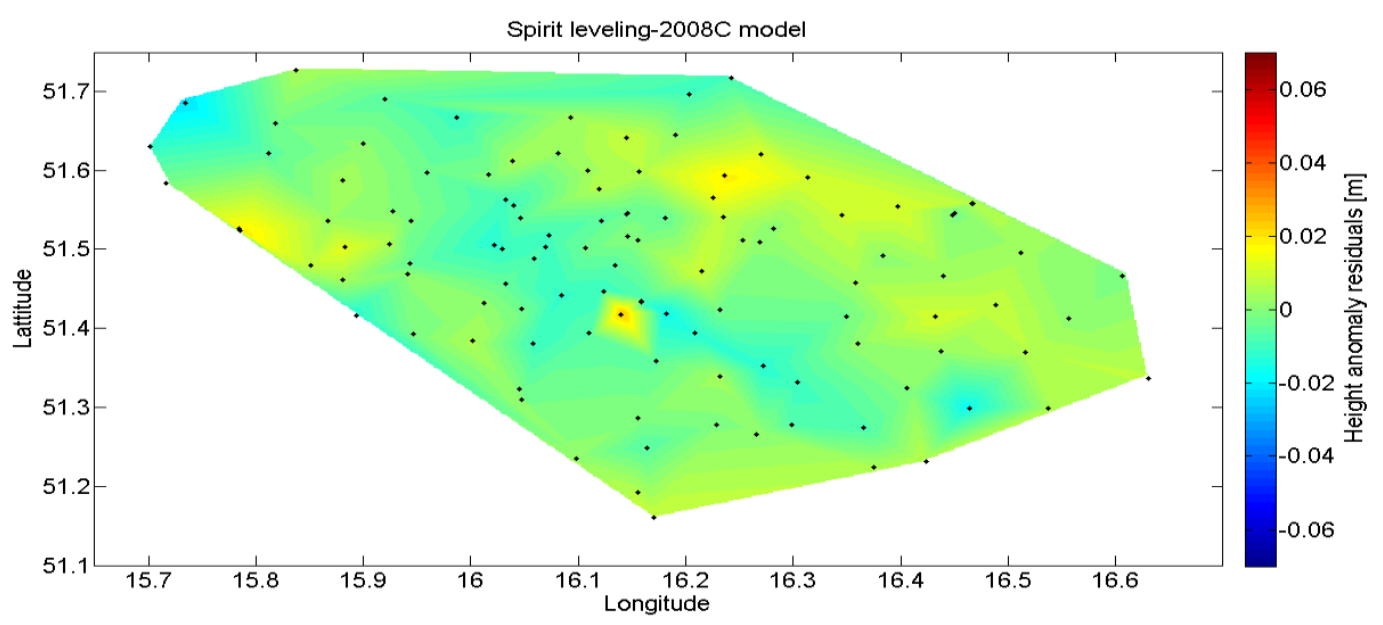

Fig. 5 Height anomaly residuals of the $2008 \mathrm{C}$ model.

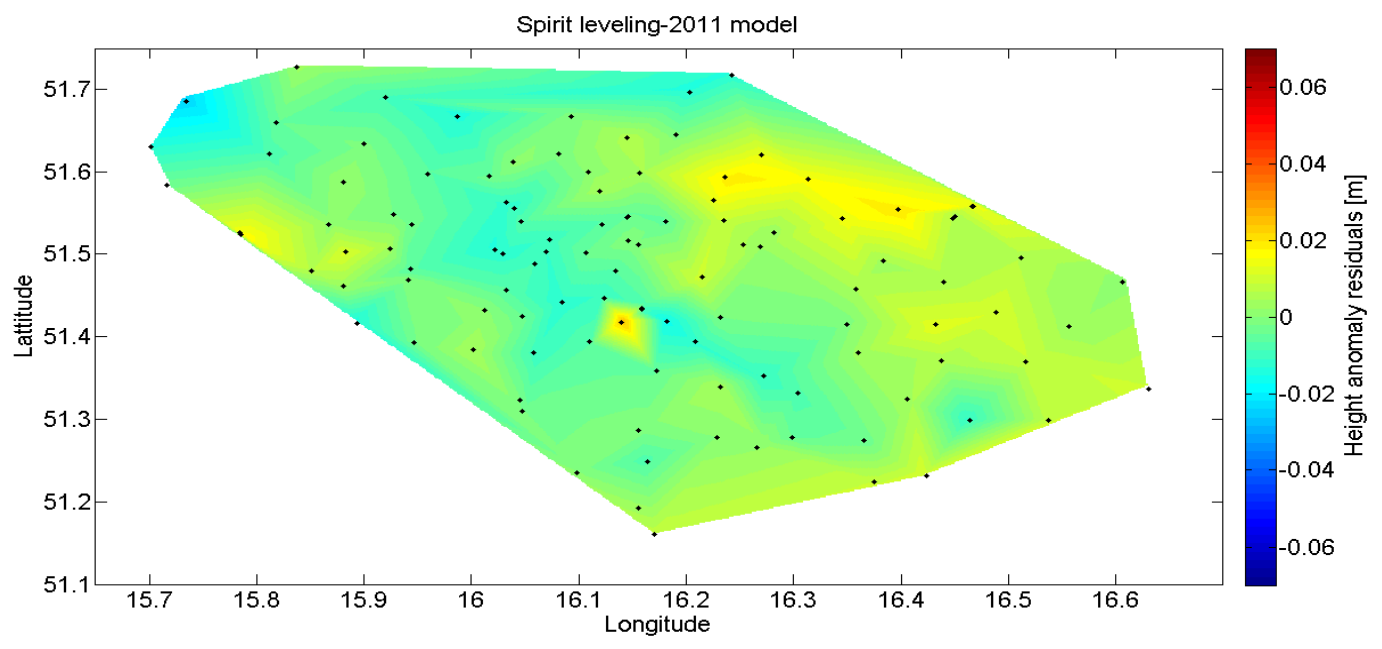

Fig. 6 Height anomaly residuals of the 2011 model.

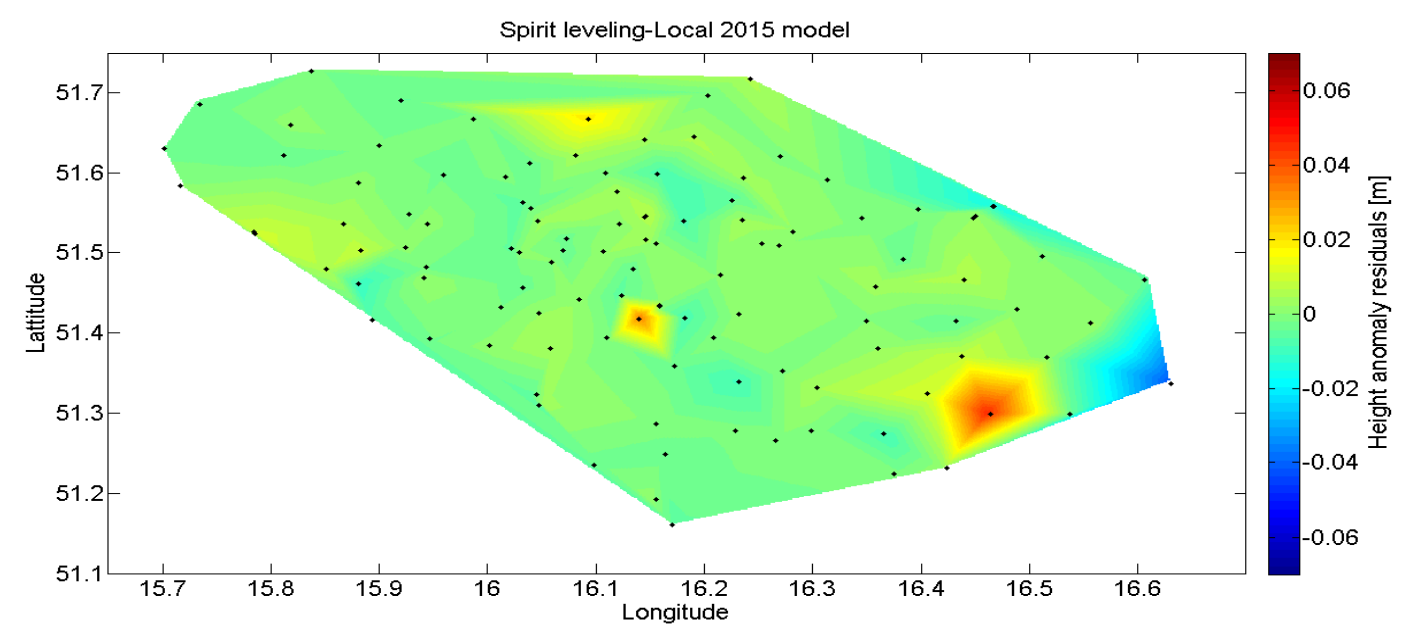

Fig. 7 Height anomaly residuals of the LGOM 2015 model. 
Table 5 Standard deviation, mean, min., max. values of height anomaly residuals after application of individual GNSS antennas calibration for satellite leveling and selected quasigeoid models. All values in [m].

\begin{tabular}{|c|c|c|c|c|c|c|}
\hline Geoid Model & & $\begin{aligned} & 2001 \\
+ & \text { PCO correction }\end{aligned}$ & & $\begin{aligned} & 2008 \\
+ & \text { PCO correction }\end{aligned}$ & & $\begin{array}{l}2008 \mathrm{~A} \\
+\mathrm{PCO} \text { correction }\end{array}$ \\
\hline Mean & -0.0386 & -0.0343 & -0.0302 & -0.0258 & -0.0226 & -0.0182 \\
\hline STD & 0.0348 & 0.0342 & 0.0099 & 0.0097 & 0.0065 & 0.0064 \\
\hline Min. residual & -0.0726 & -0.0717 & -0.0196 & -0.0205 & -0.0156 & -0.0184 \\
\hline Max. residual & 0.0777 & 0.0750 & 0.0303 & 0.0275 & 0.0157 & 0.0129 \\
\hline Geoid Model & & $\begin{array}{l}2008 \mathrm{C} \\
+ \text { PCO correction }\end{array}$ & & $\begin{aligned} & 2011 \\
&+ \text { PCO correction } \\
&\end{aligned}$ & & $\begin{array}{l}\text { Local } 2015 \\
+ \text { PCO correction }\end{array}$ \\
\hline Mean & -0.0224 & -0.0181 & -0.0211 & -0.0168 & -0.0023 & 0.0020 \\
\hline STD & 0.0069 & 0.0070 & 0.0073 & 0.0075 & 0.0041 & 0.0046 \\
\hline Min. residual & -0.0158 & -0.0185 & -0.0154 & -0.0181 & -0.0106 & -0.0133 \\
\hline Max. residual & 0.0161 & 0.0174 & 0.0167 & 0.0180 & 0.0091 & 0.0100 \\
\hline
\end{tabular}

largest shifts are observed in the height component what may affect GNSS leveling accuracy. Hence, the individual relative antenna calibrations were carried out at the calibration baseline at UWM in Olsztyn (Stepniak et al., 2015) and the obtained corrections to the IGS PCOs were used in the processing. Table 4 shows the list of and the corrections for applied GNSS.

The obtained PCO corrections were applied to the test data. New results are shown in Table 5. In case of PL-geoid-2011 model, the average value of the difference anomaly height changed from $-0.0211 \mathrm{~m}$ to $-0.0168 \mathrm{~m}$. It is possible to notice that the standard deviation values did not changed significantly. In addition, the maximum and minimum values of the residuals improved in case of leveling geoid 2001; geoidpol2008, geoidpol2008A models. However, for geoidpol2008C, PL-geoid-2011 and LGOM 2015 models the results are slightly worse. Using corrections for the PCO did not affect significantly on the differences in the shape between the analyzed quasigeoid models and the quasigeoid model based on the satellite leveling, which can be concluded analyzing the standard deviations of heights residuals. On the other hand the mean biases of the models' surfaces were reduced (i.e., average values of height anomaly differences). The reason that we noticed only very minor improvement may be due to fact that a vast majority of the antennas present corrections very close to zero, and only a few antennas have significant corrections (Table 4). Moreover, three out five corrected antennas have very similar corrections ranging from 5.6 to $6.3 \mathrm{~mm}$ that cancel out when forming baselines.

\section{SUMMARY AND CONCLUSIONS}

In this paper we investigated the performance of the application of the existing geoid models for the territory of Poland to satellite leveling in precise local network, where over $1000 \mathrm{~km}$ of the leveling lines were surveyed. Analyzes of the standard quasigeoid models and recently developed local leveling geoid 2015 (LGOM 2015) model showed that the local model is the most accurate one.

On the basis of this research it can be concluded that recently developed LGOM 2015 model can be used for precise applications such as satellite leveling over the test area. As for the regional models, the best results were obtained using EGM2008 model corrections. The final accuracy of the satellite leveling with application of the EGM2008 model was better than $\pm 1 \mathrm{~cm}$.

In order to obtain high accuracy of the satellite leveling, it is necessary to use the state of the art equipment and data processing software and algorithms. This approach allows eliminate or at least greatly reduce systematic errors. Moreover, the previous studies showed that the influence of the PCO and PCV may be a source of additional error and shifts may be observed especially in the height component what may affect GNSS leveling accuracy. Therefore, the individual relative antenna calibrations were carried out in the processing. It was also confirmed that the key issue in satellite leveling is the choice of appropriate quasigeoid model.

\section{ACKNOWLEDGEMENTS}

This research was supported by grant agreed by the decision UMO-2013/11/N/ST10/00757 from Polish National Science Center.

\section{REFERENCES}

Bilker, M., Ollikainen, M. and Poutanen, M.: 2003, Evaluation of geoid models with GPS/leveling points in Sweden and Finland. First CHAMP Mission Results for Gravity. Magnetic and Atmospheric Studies, 159-164.

DOI: $10.1007 / 978-3-540-38366-6 \_24$ 
Benahmed Daho, S.A.: 2010. Assessment of the EGM2008 gravity field in Algeria using gravity and GPS/Leveling data. Gravity. Geoid and Earth Observation. S.P. Mertikas (ed.). International Association of Geodesy Symposia, Springer-Verlag Berlin Heidelberg, 135, 459-466. DOI: 10.1007/978-3-642-10634-7 61

Boehm, J., Niell, A., Tregoning, P. and Schuh, H.: 2006, Global Mapping Function (GMF): A new empirical mapping function based on numerical weather model data. Geophysical Research Letters, 33, No. 7. DOI: 10.1029/2005GL025546

Cellmer, S., Paziewski, J. and Wielgosz, P.: 2013, Fast and precise positioning using MAFA method and new GPS and Galileo signals. Acta Geodyn. Geomater., 10, 4(172), 393-400. DOI: 10.13168/AGG.2013.0038

Chen, G. and Herring, T.A.: 1997, Effects of atmospheric azimuthal asymmetry on the analysis of space geodetic data. Journal of Geophysical Research, Solid Earth, 102, Issue B9, 20489-20502. DOI: $10.1029 / 97 \mathrm{JB} 01739$

Dach, R., Lutz, S., Walser, P. and Fridez, P. (Eds): 2015, Bernese GNSS Software Version 5.2. User manual. Astronomical Institute, University of Bern, Bern Open Publishing. DOI: 10.7892/boris.72297

Dawidowicz, K.: 2013, Impact of different GNSS antenna calibration models on height determination in the ASG-EUPOS network: a case study. Survey Review, 45, 332, 386-394. DOI: $10.1179 / 1752270613$ Y.0000000043

Dow, J.M., Neilan, R. E. and Rizos, C.: 2009, The International GNSS Service in a changing landscape of Global Navigation Satellite Systems. Journal of Geodesy, 83, 3-4, 191-198. DOI: $10.1007 / \mathrm{s} 00190-008-0300-3$

Gao, Y., Lahaye, F., Héroux, P., Liao, X., Beck, N. and Olynik, M.: 2001, Modeling and estimation of C1-P1 bias in GPS receivers. Journal of Geodesy, 74, 9, 621626. DOI: $10.1007 / \mathrm{s} 001900000117$

Kotsakis, C. and Katsambalos, K.: 2010, Quality analysis of global geopotential models at 1542 GPS/leveling benchmarks over the Hellenic mainland. Survey Review, 42, 318, 327-344. DOI: $10.1179 / 003962610 \times 12747001420500$

Krynski, J. and Łyszkowicz, A.: 2006, Centimetre quasigeoid modelling in Poland using heterogeneous data. Proceedings of the 1st International Symposium of the International Gravity Field Service (IGFS), August 28 - September 1, 2006, Istanbul, Turkey, 123127.

Kuczynska-Siehien, J., Lyszkowicz, A. and Birylo, M.: 2016, Geoid determination for the area of Poland by the least squares modification of Stokes' formula. Acta Geodyn. Geomater., 13, 1(181), 19-26. DOI: 10.13168/AGG.2015.0041

Li, X., Zhang, X., Ren, X., Fritsche, M., Wickert, J. and Schuh, H.: 2015a, Precise positioning with current multi-constellation Global Navigation Satellite Systems: GPS, GLONASS, Galileo and BeiDou. Scientific Reports, 5, 8328. DOI: 10.1038/srep08328

Li, X., Ge, M., Dai, X., Ren, X., Fritsche, M., Wickert, J. and Schuh, H.: 2015b, Accuracy and reliability of multi-GNSS real-time precise positioning: GPS, GLONASS, BeiDou, and Galileo. Journal of Geodesy, 89, 6, 607-635. DOI: 10.1007/s00190-015-0802-8
Odolinski, R., Teunissen, P.J.G. and Odijk, D.: 2014, Combined BDS, Galileo, QZSS and GPS singlefrequency RTK. GPS Solution, 19, 1, 151-163. DOI: 10.1007/s10291-014-0376-6

Pavlis, N.K., Holmes, S.A., Kenyon, S.C. and Factor, J.K.: 2012, The development and evaluation of the Earth Gravitational Model 2008 (EGM2008). J. Geophys. Res., 117, B04406. DOI: $10.1029 / 2011 \mathrm{JB} 008916$

Paziewski, J. and Wielgosz, P.: 2014, Assessment of GPS + Galileo and multi-frequency Galileo single-epoch precise positioning with network corrections. GPS Solutions, $18,4,571-579$. DOI: $10.1007 / \mathrm{s} 10291-013-0355-3$

Paziewski, J. and Wielgosz, P.: 2016, Investigation of some selected strategies for multi-GNSS instantaneous RTK positioning. Advances in Space Research. DOI: $10.1016 /$ j.asr.2016.08.034

Pażus, R., Osada, E. and Olejnik, S.: 2002, Leveling geoid 2001. Magazyn Geoinformacyjny GEODETA, 5 (84), (in Polish).

Schmid, R. and Rothacher, M.: 2003, Estimation of elevation-dependent satellite antenna phase center variations of GPS satellites. Journal of Geodesy, 77, 440-446. DOI: $10.1007 / \mathrm{s} 00190-003-0339-0$

Schmitz, M., Wübbena, G. and Boettcher, G.: 2002, Tests of phase center variations of various GPS antennas and some results. GPS Solutions, 6, 1-2, 18-27.

DOI: 10.1007/s10291-002-0008-4

Sheng, L.: 2005, The Feasibility of Replacing Precise Leveling with GPS for Permafrost Deformation Monitoring, Ph.D. dissertation, University of Calgary, Canada.

Stepniak, K., Baryła, R., Wielgosz, P. and Kurpiński, G.: 2013, Optimal data processing strategy in precise GPS leveling networks. Acta Geodyn Geomater, 10, 4(172), 443-452. DOI: 10.13168/AGG.2013.0044

Stepniak, K., Wielgosz, P. and Baryła, R.: 2015, Field tests of L1 Phase Centre variation models of surveyinggrade GPS antennas. Studia Geophysica et Geodaetica, 59, 3, 394-408. DOI: $10.1007 / \mathrm{s} 11200-014-0250-6$.

Wielgosz, P., Paziewski, J. and Baryła, R.: 2011, On constraining zenith tropospheric delays in processing of local GPS networks with Bernese software. Surv. Rev., 43, 472-83. DOI: $10.1179 / 003962611 X 13117748891877$

Wielgosz, P., Krukowska, M., Paziewski, J., KrypiakGregorczyk, A., Stepniak, K., Kapłon, J., Sierny, J., Hadaś, T. and Bosy, J.: 2013, Performance of ZTD models derived in near real-time from GBAS and meteorological data in GPS fast-static positioning. Measurement Science and Technology, 24, 12, 125802. DOI: $10.1088 / 0957-0233 / 24 / 12 / 125802$

Xu, G.: 2007, GPS: Theory. Algorithms and Applications, 2nd ed. Berlin Heidelberg Springer-Verlag. 